\title{
Correlation of Total Polyphenolic Content with Antioxidant Activity of Hydromethanolic Extract and Their Fractions of the Salvia officinalis Leaves from Different Regions of Morocco
}

\author{
Zakaria Khiya ${ }^{10},{ }^{1,2}$ Yassine Oualcadi, ${ }^{3}$ Abderrahmane Gamar, ${ }^{1,2}$ Fatima Berrekhis, ${ }^{3}$ \\ Touria Zair, ${ }^{1,2,3}$ and Fatima EL Hilali ${ }^{1,2}$ \\ ${ }^{1}$ Research Team of Chemistry of Bioactive Molecules and the Environment,Faculty of Science, University of Moulay Ismail, \\ BP 11201 Zitoune, Meknès, Morocco \\ ${ }^{2}$ Laboratory of Materials Chemistry and Biotechnology of Natural Products, Faculty of Science, University of Moulay Ismail, \\ BP 11201 Zitoune, Meknès, Morocco \\ ${ }^{3}$ Physical Chemistry of Materials Team, Cadi Ayyad University (ENS), BP 2400, Marrakech, Morocco
}

Correspondence should be addressed to Zakaria Khiya; khiya.zakaria@gmail.com

Received 14 May 2020; Revised 24 November 2020; Accepted 21 January 2021; Published 8 February 2021

Academic Editor: Mohamed Azaroual

Copyright @ 2021 Zakaria Khiya et al. This is an open access article distributed under the Creative Commons Attribution License, which permits unrestricted use, distribution, and reproduction in any medium, provided the original work is properly cited.

\begin{abstract}
The purpose of this study is to determine the total content of phenols, flavonoids, and condensed tannins, as well as on the antioxidant activity of the extract, and their fractions were measured by 2,2-diphenyl-1-picrylhydrazyl (DPPH), ferric reducing antioxidant power (FRAP), phosphomolybdate reduction (or total antioxidant capacity), and cyclic voltammetry (CV). The hydromethanolic extract of Salvia officinalis showed the highest values of total phenolic (176 mgGAE/g of extract) and condensed tannins $(162.53 \mathrm{mgEC} / \mathrm{g}$ of extract) from the Boulemane and Khenifra regions, respectively. The results showed that the best DPPH assay was found in the ethyl acetate fraction of Salvia officinalis leaves of the Boulemane region (IC $50=0.002 \mathrm{mg} / \mathrm{ml}$ ). For the ethyl acetate and butanolic fractions of Salvia officinalis leaves, those collected from different regions have a better reducing capacity $\left(\mathrm{EC}_{50}=0.021 \mathrm{mg} / \mathrm{ml}\right.$, respectively). For the total antioxidant capacity, the best activity was found in the aqueous fraction of Salvia officinalis leaves of the Boulemane region (108 mgGAE/g of extract). By the cyclic voltammetry method, hydromethanolic extract of Salvia officinalis leaves from the Boulemane region showed an important result (288.8 mgGAE/g). There was a positive correlation between total phenol content (TPC), condensed tannin content (TCT), and total antioxidant capacity (TAC) ( $r=0.932, r=0.896$, respectively). The main compounds that have been identified in the hydromethanolic extract of Salvia officinalis are ascorbic acid, gallic acid, 4-hydroxybenzoic acid, tannic acid, and rutin. Due to their antioxidant property, the leaf extracts from Salvia officinalis are used as natural preservative ingredients in food and/or pharmaceutical industries.
\end{abstract}

\section{Introduction}

The medicinal and aromatic plants have a considerable content of bioactive compounds with specific biochemical or organoleptic properties, allowing their use in the pharmaceutical, cosmetic, or food industries and biopesticides. Despite the progress made in the research on synthetic drugs, plants and their products are still considered the main sources of medicines and have a great use in the pharmaceutical industry [1]. Several epidemiological studies suggest that antioxidant-rich plants play a protective role in health and disease [2], and their consumption has lowered the risk of cancer, heart disease, and hypertension [3]. The main compounds of phytochemicals that can contribute to the total antioxidant capacity of the plant include polyphenols and vitamins (C and $\mathrm{E})$. The phenolic compounds of the plants are hydroxyderivatives of benzoic acid and cinnamic acids and have been reported as having antioxidant and anticarcinogenic effects. The phenolic compounds, including flavonoids, are important in plant defense mechanisms against invasive bacteria and other types of environmental stress [4]. It has long been recognized that flavonoids have 
anti-inflammatory, antiallergic, antiviral, and antiproliferative activities $[4,5]$. Several reports indicate that the antioxidant potential of medicinal plants may be related to the concentration of their phenolic compounds which include phenolic acids, flavonoids, anthocyanins, and tannins [6]. These compounds are of great value to prevent appearance or progression of many human diseases [7]. The antioxidants are compounds that help to retard or inhibit lipid oxidation and when added to foods tend to minimize rancid, slow the formation of toxic oxidation products, help maintain the nutritional quality, and increase their shelf life [8]. Indeed, their role as natural antioxidants allows the body to fight against a large number of diseases, which is increasingly of interest for the prevention and treatment of cancer [9], inflammatory [10], cardiovascular [11], and neurodegenerative diseases [12].

Among 900 species of the genus Salvia of Lamiaceae family [13], there are well-known representatives from ancient times for their curative properties, including S. officinalis, one of the earliest traditionally used species [13]. Salvia officinalis is a plant of immense commercial importance. Because of its flavoring properties, this plant has been widely used in the preparation of many foods. In popular medicine from Asia and Latin America, it has been used for the treatment of different types of disorders including seizure, ulcers, gout, rheumatism, inflammation, dizziness, tremors, paralysis, diarrhea, and hyperglycemia [14]. In traditional medicine in Europe, S. officinalis L. has been used to treat mild dyspepsia, excessive sweating, age-related cognitive impairment, and inflammatory in the throat and skin [15]. It is considered as a stimulant for anemic people, also for stressed and depressed people, and advised for students during the exam period. Moreover, it is applied in gargle against inflammatory of the mouth, abscesses, and also for the cleaning and healing of wounds. The commercial importance of the plant Salvia officinalis is due to the richness of phenolic and volatile compounds such as essential oil. It occupies an important place in the cosmetic food industries because of its biological properties. However, the polyphenols and essential oils of Salvia officinalis also possess biological properties such as antibacterial [16], antioxidant, antitumor [14], antinociceptive, and anti-inflammatory activities [17] and cytotoxic and cytogenetic effects [18]. The results of several studies suggest that $S$. officinalis has a power antioxidant activity. The phenolic compounds are isolated from the extract of Salvia officinalis such as carnosol, rosmarinic, and carnosic acids, followed by caffeic acid, rosmanol, rosmadial, genkwanin, and cirsimaritin with the most effective antioxidant activity [19]. In addition, rosmarinic acid and flavonoids of $S$. officinalis especially quercetin and rutin have stronger antioxidant activity [20].

The aim of this study was to study the total content of phenols, flavonoids, and condensed tannins and the antioxidant activity of the hydromethanolic extract and its fractions by ethyl acetate and $n$-butanol of Salvia officinalis L. obtained from different regions of Morocco. The different methods used to evaluate the antioxidant activity are scavenging of free radicals $(\mathrm{DPPH})$, reduction of iron
(FRAP), reduction of phosphomolybdate (or total antioxidant capacity), and cyclic voltammetry (CV).

\section{Methods and Materials}

2.1. Plant Sample. Salvia officinalis is a plant of immense commercial importance. Because of its flavoring properties, this plant has been widely used in the preparation of many foods. The leaves of S. officinalis L. were collected in April 2017 from two different regions Khenifra and Boulemane of Morocco. Only the aerial part (leaves) were collected and dried for 15 days in the shade at room temperature. The plant sample was identified in the Ecology Department of Scientific Institute of Rabat, Morocco, Mohammed V University. The voucher specimen (No. 2938) was deposited in the Herbarium of the Scientific Institute of Rabat.

2.2. Phytochemical Screening Tests. The phytochemical screening is the main way to highlight the abundant families of secondary metabolites in the studied plant extracts. This screening has focused either on the formation of insoluble complexes using precipitation reactions or the formation of a complex colored using colored reactions. The characterization of different chemical groups was done according to experimental protocols [21], and the most commonly used operations are maceration, infusion, and decoction.

\subsection{Preparation of Crude Extract by Solid-Liquid Extraction} (SLE) and Their Fractionation by Liquid-Liquid Extraction (LLE) ofS. officinalis. The plant Salvia officinalis was dried in a dry and ventilated place, protected from sunlight. Then, it was crashed completely and weighed $(M=30 \mathrm{~g})$. The leaves of Salvia officinalis were extracted by solvent using the Soxhlet method in a hydroalcoholic mixture methanol: water $(70: 30, v / v)$, for 6 hours. The extracts were filtered with Whatman filter paper, and the filtrate is evaporated under reduced pressure by using rotavapor (1st step) (Figure 1) and recovered with distilled water and partitioned successively using ethyl acetate and $n$-butanol (2nd step) (Figure 1). The extracts were concentrated and redissolved and kept at $6^{\circ} \mathrm{C}$. We have obtained the following: hydromethanolic extract $(\mathrm{MeOH})$, ethyl acetate fraction (EtOAc), and butanol fraction $(\mathrm{BuOH})$.

2.4. Determination of Total Phenol Content (TPC). Total phenol content (TPC) in the extracts of Salvia officinalis was determined by method using the Folin-Ciocalteu reagent [22]. In brief, $20 \mu \mathrm{l}$ of the extract was mixed with $1.5 \mathrm{ml}$ of Folin-Ciocalteu reagent (10\%). After $10 \mathrm{~min}, 1.5 \mathrm{ml}$ of sodium carbonate is added $\left(\mathrm{Na}_{2} \mathrm{CO}_{3}\right)$, and finally, the mixture was diluted with distilled water. After 2 hours incubation at room temperature, the absorbance was measured at $760 \mathrm{~nm}$. The TPC concentration was determined from standard gallic acid curve equation $(y=0.095 x+0.003)$, and the results were expressed as mg gallic acid equivalents per gram of extract (mgGAE/g of extract). 


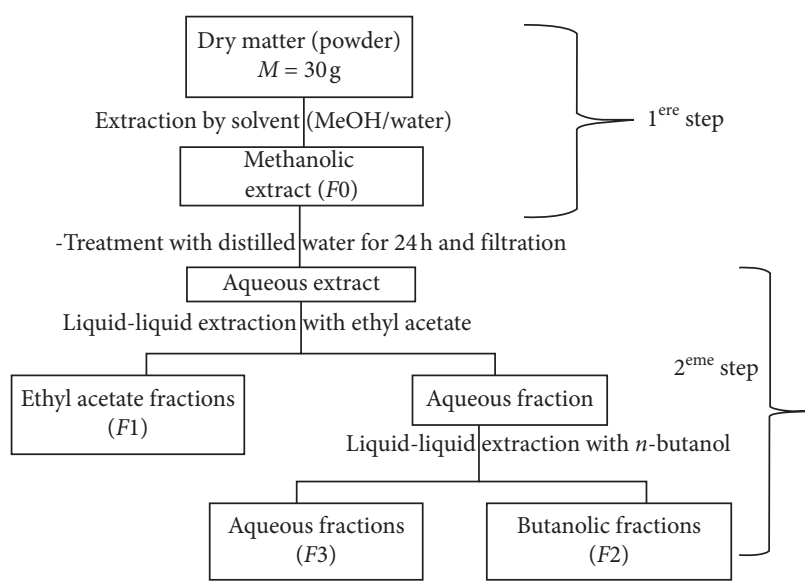

Figure 1: The fractionation step adopted for splitting into four fractions $(F 0, F 1, F 2$, and $F 3)$ of the hydromethanolic extract of Salvia officinalis leaf from two regions with $F 0$ hydromethanolic extract and F1, F2, and F3: ethyl acetate, butanolic, and aqueous fractions, respectively.

2.5. Determination of Total Flavonoid Content (TFC). Total flavonoid content (TFC) in the extracts of Salvia officinalis was estimated by the colorimetric method using aluminium chloride [23]. In brief, $0.1 \mathrm{ml}$ of $10 \%$ of $\mathrm{AlCl}_{3}$ methanol solution was added to $40 \mu \mathrm{l}$ of extract. After that, the mixture solution was diluted with $20 \mathrm{ml}$ distilled water and completed with absolute methanol at $50 \mathrm{ml}$ and then left 2 hours in the dark. The absorbance was measured at 433. The total flavonoid concentration of the extract was determined from standard quercetin curve equation $((y=0.073 x-0.081)$, and the results were expressed as $\mathrm{mg}$ quercetin equivalents per gram of extract (mgQE/g of extract).

2.6. Determination of Condensed Tannin Content. Total tannin content (TTC) was estimated by using the vanillin assay method [23]. $3 \mathrm{ml}$ of the vanillin/methanol solution $(4 \%, \mathrm{w} / \mathrm{v})$ and $1.5 \mathrm{ml}$ of concentrated hydrochloric acid were added to $20 \mu \mathrm{l}$ of extract and allowed to react at room temperature for $20 \mathrm{~min}$. The absorbance was measured at $499 \mathrm{~nm}$. The total condensed tannin concentration of the extract was determined from standard catechin curve equation $(y=0.158 x+0.0026)$, and the results were $\mathrm{mg}$ catechin equivalents per gram of the extract $(\mathrm{mgCE} / \mathrm{g}$ of extract).

2.7. Identification of Phenolic Compounds by HPLC. The qualitative analysis of phenolic compounds was performed using a HPLC Jasco LC-4000 system (Jasco International Corporation, Tokyo, Japan), consisted of quaternary pump (PU-4180) DAD detector as described previously by Skendi et al. [24] and a reversed-phase column (Nucleodur 100$5 \mu \mathrm{m} \mathrm{C}_{18}(250 \mathrm{~mm} \times 4.6 \mathrm{~mm})$. The mobile phase consists of three solvents: (A) $1 \%$ acetic acid in water, (B) acetonitrile, and $(\mathrm{C})$ methanol, and the following gradient program was performed: at $0 \mathrm{~min}$, the proportion of $\mathrm{A}: \mathrm{B}: \mathrm{C}$ was $90: 0: 0$; at $10 \mathrm{~min}, 80: 4: 16$; at $25 \mathrm{~min}, 75: 5: 20$; at $30 \mathrm{~min}, 65: 5: 30$; at
$31 \mathrm{~min}, 40: 0: 60$; at $37 \mathrm{~min}, 35: 20: 45$; and at $50 \mathrm{~min}, 20: 80$ : 0 . The system was allowed to operate for another $5 \mathrm{~min}$ at $100 \%$ of B in order to clean the column before rebalancing it with the initial conditions. The mobile phase flow rate was $1.3 \mathrm{ml} / \mathrm{min}$. The injection volume was $50 \mu \mathrm{l}$ of the hydromethanolic extract $(F 0)$, and the detection was performed by $\mathrm{UV}-\mathrm{V}$ is spectroscopy to measure the absorbance at wavelengths equal to 260 and $330 \mathrm{~nm}$. The identification of phenolic compounds was made by comparing retention times and spectra with those of standard commercially available compounds.

\subsection{Evaluation of Antioxidant Activity}

2.8.1. DPPH $H^{\bullet}$ Method (2,2-Diphenyl-1-picrylhydrazyl). The DPPH radical solution is prepared in advance by dissolving $2.4 \mathrm{mg}$ of $\mathrm{DPPH}^{\bullet}$ in $100 \mathrm{ml}$ of absolute ethanol. The series of dilutions of the Salvia officinalis extract were prepared in ethanol solvent. In brief, $200 \mu \mathrm{l}$ of various concentrations of extracts prepared in ethanol solvent was mixed with $2.8 \mathrm{ml}$ of DPPH ethanol solution. Finally, the solutions were incubated for $30 \mathrm{~min}$ in the dark at room temperature. The reaction of the DPPH radical was estimated by measuring the absorption at $515 \mathrm{~nm}$, and ascorbic acid was used as a positive control. The percentage of inhibition of $\mathrm{DPPH}^{\bullet} \cdot(\mathrm{PI} \%)$ was calculated as follows [23]:

$$
\mathrm{PI} \%=\left(\frac{A_{0}-A_{1}}{A_{0}}\right) \times 100,
$$

with $A_{0}$ as absorbance of the solution containing only $\mathrm{DPPH}^{\bullet}$ radical solution as a negative control and $A_{1}$ as absorbance of the sample solution in the presence of DPPH${ }^{\bullet}$.

The half-inhibitory concentration $\mathrm{IC}_{50}$ was determined from the inhibition percentage (PI\%) curve as a function of the extract concentrations; the lower the value of $\mathrm{IC}_{50}$ is, the more the extract is powerful with respect to the radicals.

2.8.2. FRAP Method (Ferric Reducing Antioxidant Power). The reducing power of the plant extract was determined by applying the method described by Lim et al. [25], and $1 \mathrm{ml}$ of extract at different concentrations $(0-1 \mathrm{mg} / \mathrm{ml})$ were mixed with $2.5 \mathrm{ml}$ of the phosphate buffer solution $(0.2 \mathrm{M}$, $\mathrm{pH}=6.6)$ and $2.5 \mathrm{ml}$ of potassium ferricyanide $\left[\mathrm{K}_{3} \mathrm{Fe}(\mathrm{CN})_{6}\right]$ (1\%). The mixtures were incubated at $50^{\circ} \mathrm{C}$ for $20 \mathrm{~min}$, followed by addition of $2.5 \mathrm{~mL}$ of $10 \%(\mathrm{w} / \mathrm{v})$ trichloroacetic acid. The mixture was then centrifuged at $3000 \mathrm{rpm}$ for $10 \mathrm{~min}$. After $10 \mathrm{~min}, 2.5 \mathrm{ml}$ of the mixture was mixed with $2.5 \mathrm{ml}$ of distilled water and $0.5 \mathrm{ml}$ of $\left[\mathrm{FeCl}_{3}, 6 \mathrm{H}_{2} 0\right](0.1 \%)$ was added to it. The absorbance was read at $700 \mathrm{~nm}$, using ascorbic acid as a positive control. The concentration $\mathrm{EC}_{50}$, which is defined as the effective concentration at which the absorbance is equal to 0.5 , is the index used to compare and express the potency of the reducing capacities of bioactive substances [26].

2.8.3. Phosphomolybdate Method (or Total Antioxidant Capacity). The total antioxidant polyphenols capacity of 
Salvia officinalis L. was evaluated by the phosphomolybdate method according to the procedure of Prieto et al. [27]. In brief, $20 \mu \mathrm{l}$ of the extract was mixed with $1 \mathrm{ml}$ of the reagent solution ( $0.6 \mathrm{M}$ sulfuric acid, $28 \mathrm{mM}$ sodium phosphate, and $4 \mathrm{mM}$ molybdate ammonium). The mixtures were incubated at $95^{\circ} \mathrm{C}$ for $90 \mathrm{~min}$. The absorbance was determined at $695 \mathrm{~nm}$, using $1 \mathrm{ml}$ of the reagent solution $(0.6 \mathrm{M}$ sulfuric acid, $28 \mathrm{mM}$ sodium phosphate, and $4 \mathrm{mM}$ molybdate ammonium) and $1 \mathrm{ml}$ of methanol as a negative control. The total antioxidant capacity (TAC) concentration was determined from standard gallic acid curve equation $(y=0.902 x+0.036)$, and the results were expressed as $\mathrm{mg}$ gallic acid equivalents per gram of extract (mgGAE/g of extract).

2.8.4. Cyclic Voltammetry. The dissolved extracts in the sodium acetate buffer solution-acetic acid $0.1 \mathrm{M}$ at $\mathrm{pH}=3.6$ as a support electrolyte were prepared for analysis. The calibration curves were constructed with gallic acid solutions that were also dissolved in the sodium acetate-acetic acid $0.1 \mathrm{M}$ buffer solution at $\mathrm{pH}=3.6$. The total antioxidant activity (TAA) obtained by electrochemical methods was expressed in terms of gallic acid equivalent. Cyclic voltammograms were achieved from zero to $1000 \mathrm{mV}$ at a scan rate of $25 \mathrm{mV} / \mathrm{s}$. All measurements were made at room temperature using a conventional three-electrode system consisting of a glass carbon-working electrode $(3 \mathrm{~mm}$ diameter), a platinum auxiliary electrode, and a reference electrode Ag/AgCl. Before each measurement, electrolyte solutions were desecrated with an inert gas $\left(\mathrm{N}_{2}\right)$ for $5 \mathrm{~min}$.

\section{Result and Discussion}

3.1. Phytochemical Screening. The results of the phytochemical tests performed on the extracts of Salvia officinalis leaves of the two regions Khenifra and Boulemane show the abundant presence of catechin and gallic tannins, sterols, and triterpenes; on the other hand, we see a less abundant presence of flavonoids. However, mucilages, alkaloids, and saponins are absent in Salvia officinalis leaves. The work achieved out by Mekhaldi et al. showed that the Salvia officinalis extract present tannins, flavonoids, terpenoids, and sterols, but alkaloids and saponins are absent [28]. Another study focused on S. verbenaca where the same phytochemical families were identified after extracting the aerial part of the plant, and this showed the presence of condensed tannins, flavonoids, cardiac glycosides, and the absence of mucilage.

\subsection{Total Concentration of Phenol (TPC), Flavonoid (TFC),} and Condensed Tannin (TCT) of Salvia officinalis L. The phenolic total concentration (TPC), flavonoid (TFC), and condensed tannin (TCT) of the hydromethanolic extract and their fractions of ethyl acetate, butanolic, and aqueous of Salvia officinalis L. of both regions (Boulemane and Khenifra) were calculated from the calibration curve of gallic acid (mgGAE/g of extract), quercetin (mgQE/g of extract), and catechin (mgCE/g of extract) (Table 1).
The TPC concentration of the leaves of Salvia officinalis was measured using the Folin-Ciocalteu method. The values varied from 70.5 to $176.5 \mathrm{mgGAE} / \mathrm{g}$ of extract in two regions (Khenifra and Boulemane), and the highest TPC concentration was observed in the hydromethanolic extract and aqueous fraction (Khenifra 176 and Boulemane $85.1 \mathrm{mgGAE} / \mathrm{g}$ of extract). TFC and TTC concentrations of the plant extracts were also measured (Table 1); for TFC concentration, the values ranged from $1.92 \mathrm{mgQE} / \mathrm{g}$ of extract for butanolic fraction of Salvia officinalis from Khenifra region to $9.1 \mathrm{mgQE} / \mathrm{g}$ of extract for the hydromethanolic extract of Salvia officinalis from Boulemane region. However, the levels of TTC concentration varied from 0.42 to $162.53 \mathrm{mgCE} / \mathrm{g}$ of extract, and the highest level TTC concentration was remarked in the aqueous fraction of Salvia officinalis in the Boulemane region $(162.53 \mathrm{mgCE} / \mathrm{g}$ of extract).

Their values can be compared with those of other Salvia species obtained by Alimpić et al. [29]. They measured a large number of phenolic compounds in aqueous extracts of Salvia amplexicaulis and Salvia ringens (226.30 and 189.01 mgGAE/g, respectively), and these values are higher than ours despite the fact that they used water extraction. This difference from our results is probably due to the preparation and extraction method, distilled water temperature, or geoclimatic factors. However, flavonoids were more abundant in the extract of S. Justicia (32.36 mgQE/g). Other work carried out by Stagos et al. showed that the highest total phenol content in the aqueous extracts from $S$. fruticosa of Greece is in the order of $190 \mathrm{mgGAE} / \mathrm{g}$ [17]. This value is higher than that found in our study although we used hydromethanolic extraction. Krimat et al. showed the phenolic and flavonoid contents in hydromethanolic extract of Salvia chudaei in the order of $39.06 \mathrm{mgGAE} / \mathrm{g}$ and $4.68 \mathrm{mgQE} / \mathrm{g}$, respectively, and this value is less than that obtained in this study [30]. Topçu et al. showed the variation in polyphenol contents relative to the polarity of the extraction solvent [31]. This difference is likely due to the fact that the assay by these reagents is not polyphenol specific, but many compounds can react with this reagent, giving an apparent high phenolic rate [32]. The contents reported by the authors are very high compared to these results, and this difference probably finds its explanation in the difference of work condition and the relationship used to calculate the content. The quantitative variability in the polyphenol content in these plant species is probably due to the variability qualitative of phenolic compounds of the plant extracts [33], to the genotypic factors [34], the biotic conditions (species, physiological organ, and stage), abiotic and the nature of the soil (edaphic factors) [35], and the type of microclimate and also the bioclimatic stages where these plants grow [36].

3.3. Identification of Phenolic Compounds by HPLC. The elution profile of the compounds derived from the methanolic extract was followed at 260 and $330 \mathrm{~nm}$, the wavelength characteristics of the phenolic (Figure 2). Indeed, all phenols are detected in the ultraviolet region with a 
TABLE 1: Total concentration of phenolic (TPC), flavonoid (TFC), and condensed tannin (TCT) of hydromethanolic extract and their fractions of ethyl acetate and butanolic of Salvia officinalis $L$.

\begin{tabular}{|c|c|c|c|c|c|c|}
\hline \multirow[b]{2}{*}{ Fractions } & \multicolumn{3}{|c|}{ Boulemane region } & \multicolumn{3}{|c|}{ Khenifra region } \\
\hline & $\begin{array}{c}\text { TPC (mgGAE/g of } \\
\text { extract) }\end{array}$ & $\begin{array}{c}\text { TFC } \\
\text { (mgQE/g of } \\
\text { extract) }\end{array}$ & $\begin{array}{c}\text { TCT } \\
\text { (mgCE/g of } \\
\text { extract) }\end{array}$ & $\begin{array}{c}\text { TPC } \\
\text { (mgGAE/g of } \\
\text { extract) }\end{array}$ & $\begin{array}{c}\text { TFC } \\
\text { (mgQE/g of } \\
\text { extract) }\end{array}$ & $\begin{array}{c}\text { TCT (mgCE/g of } \\
\text { extract }\end{array}$ \\
\hline $\begin{array}{l}\text { Hydromethanolic } \\
(F 0)\end{array}$ & 82 & 9.1 & 90.98 & 176 & 3.62 & 31.45 \\
\hline Ethyl acetate $(F 1)$ & 74.15 & 4.9 & 17.91 & 170.5 & 3.22 & 0.42 \\
\hline Butanolic $(F 2)$ & 70.5 & 5.01 & 4.16 & 172 & 1.92 & 4.37 \\
\hline Aqueous (F3) & 85.1 & 9.07 & 162.53 & 176.5 & 3.86 & 23.67 \\
\hline
\end{tabular}

maximum adsorption peak at 260 and $280 \mathrm{~nm}$ due to the presence of the phenolic cycle. The identification is based on the comparison of the different constituents retention times of the extracts with those of the different standards analyzed under the same conditions. The qualitative analysis of the Salvia officinalis extract carried out using an HPLC apparatus coupled to PDA detector is presented in Figure 2. According to the HPLC chromatogram of Salvia officinalis (Figure 2), we have identified the molecules used as standards at different wavelengths 260 and $330 \mathrm{~nm}$ in the hydromethanolic extract (F0) (Figure 2). By comparing the retention times of the standards with the molecules contained in the extract, we detected the presence of the same molecules in the hydromethanolic extract $(F 0)$. In addition, we have noticed that the chromatogram shows peaks of ascorbic acid, gallic acid, 4-hydroxybenzoic acid, tannic acid, and rutin and that they absorb at $260 \mathrm{~nm}$ more than $330 \mathrm{~nm}$. At these wavelengths, we did not identify the quercetin molecule in the extract.

3.4. Antioxidant Activity Measured by Spectrophotometry. In this study, the antioxidant capacity of $S$. officinalis extracts of plants collected of the Boulemane and Khenifra regions was evaluated using four common antioxidant methods, namely, DPPH ${ }^{\bullet}$, FRAP, TAC, and CV. DPPH is one of the most used methods to measure the ability of compounds to act as free radical scavenge. It is widely used to evaluate the antioxidant capacity of plant extracts or individual phenolic compounds. In general, DPPH is estimated by uses of the limit value (the concentration reducing to $50 \%$ of the $\mathrm{DPPH}^{\bullet}$ ). Ferric reductive antioxidant activity (FRAP) is based on the ability of antioxidants to reduce ferric ion $\left[\mathrm{Fe}^{3+}\right]$ to ferrous $\left[\mathrm{Fe}^{2+}\right]$. The mechanism is as an indicator of the donor activity of electrons, characteristic of the antioxidant action of the polyphenols [37]. The increase in absorbance in the reaction medium indicates an increase in the power of the tested extracts [38]. The phosphomolybdate method or total antioxidant capacity (TAC) is a technique based on the reduction of molybdenum $\mathrm{Mo}(\mathrm{VI})$ present in the form of molybdate ions $\mathrm{MoO}_{4}^{2-}$ to molybdenum $\mathrm{Mo}(\mathrm{V})$ $\mathrm{MoO}_{2}^{+}$in the presence of the extract to form a green complex of phosphate/ $\mathrm{Mo}(\mathrm{V})$ at acid $\mathrm{pH}$.

The results of the antioxidant activity evaluation are presented in Table 2. In general, all extracts revealed a high antioxidant activity, including free radical scavenging activity $\left(\mathrm{DPPH}^{\cdot}\right)$, power reduction (FRAP), total antioxidant capacity (TAC), and cyclic voltammetry (CV). So far, there is no simple and universal method in which antioxidant activity is evaluated qualitatively and quantitatively [39]. For this reason, we have combined four complementary techniques.

$\mathrm{DPPH}$ values of $\mathrm{IC}_{50}$ ranged between 0.002 and $0.04 \mathrm{mg} /$ $\mathrm{ml}$, and the best activity was observed in the fractions ethyl acetate and butanol of Salvia officinalis leaves in the Boulemane region 0.002 and $0.007 \mathrm{mg} / \mathrm{ml}$, respectively, which are better than the reference antioxidant ascorbic acid $0.032 \mathrm{mg} / \mathrm{ml}$. The $\mathrm{DPPH}$ values of $\mathrm{IC}_{50}$ varied from 0.068 to $0.092 \mathrm{mg} / \mathrm{ml}$ from Khenifra region (Table 2). The lowest scavenging activity was recorded in the fractions butanolic and aqueous of Salvia officinalis from Khenifra region 0.089 and $0.092 \mathrm{mg} / \mathrm{ml}$, respectively, and $\mathrm{IC}_{50}$ of the fractions of Salvia officinalis from this region was bigger than the activity of the ascorbic acid $(0.032 \mathrm{mg} / \mathrm{ml})$ (Table 2$)$. Ferric reducing activity values of $\mathrm{EC}_{50}$ ranged from 0.021 to $0.039 \mathrm{mg} / \mathrm{ml}$ in two region (Boulemane and Khenifra) (Table 2). The hydromethanolic extract and ethyl acetate fraction of Salvia officinalis leaves from Khenifra region had the best reducing activity with a value of $\mathrm{EC}_{50}=0.021$ and $0.031 \mathrm{mg} / \mathrm{ml}$. From Boulemane, ferric reducing activity was remarked in the fractions ethyl acetate and butanolic of Salvia officinalis $(0.029$ and $0.039 \mathrm{mg} / \mathrm{ml}$, respectively). The fractions ethyl acetate and butanolic for Boulemane region and hydromethanolic extract for the Khenifra region showed excellent reducing activity better than synthesis antioxidant ascorbic acid $0.032 \mathrm{mg} / \mathrm{ml}$. The results are summarized in Table 2 . The values of total antioxidant capacity (TAC) varied between 21.136 and $108 \mathrm{mgGAE} / \mathrm{g}$, and the leaves extracts of Salvia officinalis gave the higher result of reduction of Mo (VI) exactly in the aqueous fraction $103.50 \mathrm{mgGAE} / \mathrm{g}$ followed by the hydromethanolic extract $88.670 \mathrm{mgGAE} / \mathrm{g}$ from Khenifra region, while the lowest was recorded in the fraction butanolic of Salvia officinalis from the Boulemane region (60.803 mgGAE/g).

Based on the results obtained in these tests, it is evident that the interaction of an antioxidant with DPPH depends not only on the concentration but also on the structure and nature of the antioxidants. Some compounds react very quickly with the DPPH radical. Athamena et al. have also found a difference according to the test used [40]. This can explain this variation in terms of the results obtained. It is important to note that, in the FRAP test, all the reduced substances (not just phenolic compounds) react in the reaction medium [41]. In 

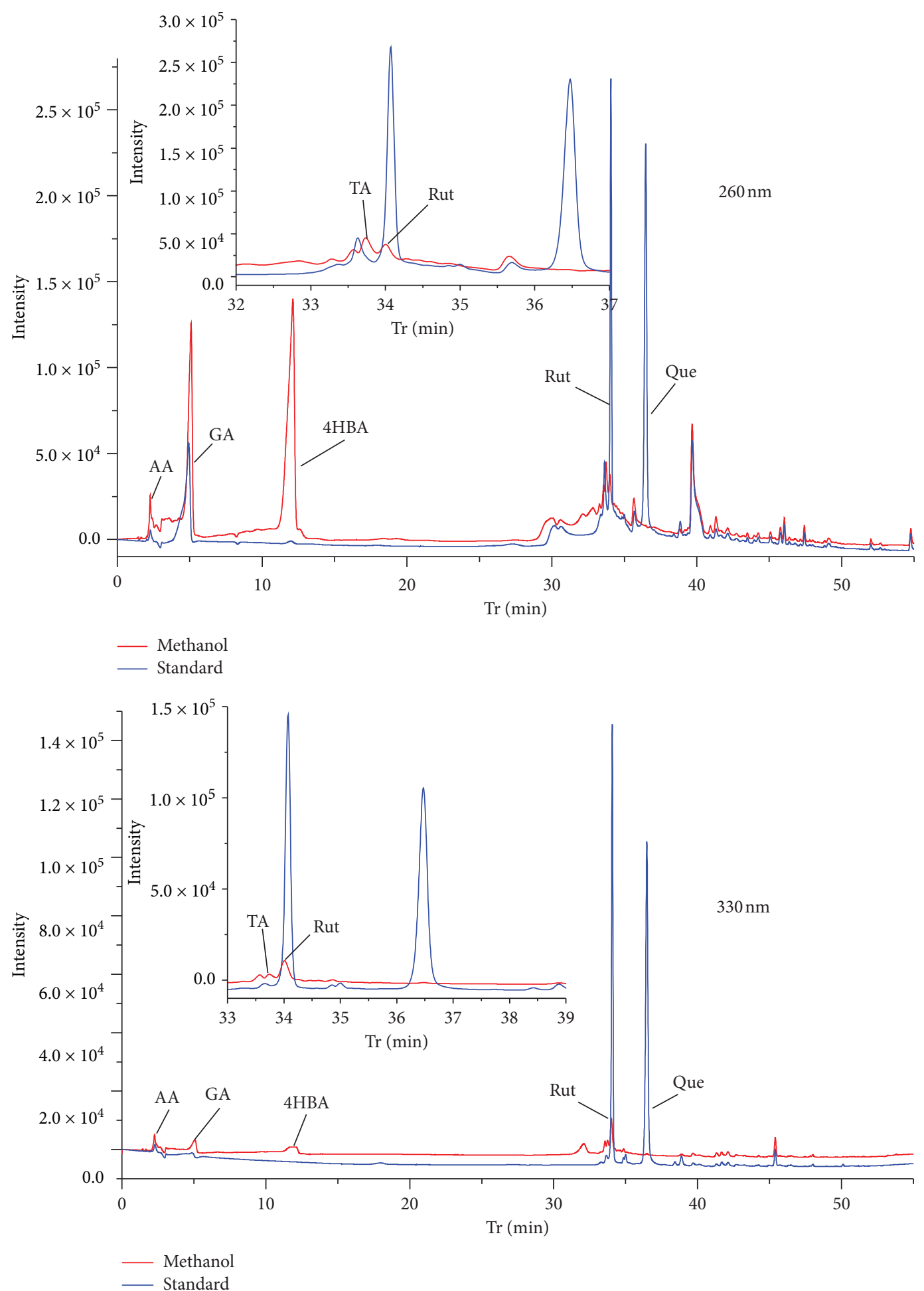

FIgURE 2: HPLC chromatograms of hydromethanolic extract Salvia officinalis and standards (GA : gallic acid; AA: ascorbic acid; 4-HBA: 4hydroxybenzoic acid; Rut: rutin; TA: tannic acid; Quer: quercetin) at wavelengths 260 and $330 \mathrm{~nm}$.

this test, hydrogen and the electron are transferred from the reducing compound (antioxidant) to the oxidizing complex (FRAP). This transfer depends on the redox potential, the $\mathrm{pH}$ of the medium, and the antioxidant compound structure. This activity may be due to the presence of phenolic acids and flavonoids such as gallic, ascorbic, tannic acids, quercetin, and rutin. According to Turkmen et al., the polyphenols appear to be effective donors of hydrogen to the DPPH radical because of their ideal structural chemistry [42]. Other minor phenolic compounds should not be neglected because the synergy between different chemicals should be taken into account in biological activity [43]. Other work carried out by Belkhiri 
TABLe 2: Antioxidant activity of the hydromethanolic extract $(F 0)$ and its fractions $(F 1, F 2$, and $F 3)$ of Salvia officinalis.

\begin{tabular}{|c|c|c|c|c|c|c|}
\hline \multirow[b]{2}{*}{ Fractions } & \multicolumn{3}{|c|}{ Boulemane region } & \multicolumn{3}{|c|}{ Khenifra region } \\
\hline & $\begin{array}{l}\text { DPPH IC } \\
(\mathrm{mg} / \mathrm{ml})\end{array}$ & $\begin{array}{l}\text { FRAP EC } \text { ER }_{50} \\
(\mathrm{mg} / \mathrm{ml})\end{array}$ & $\begin{array}{c}\text { TAC (mgGAE/g of } \\
\text { extract) }\end{array}$ & $\begin{array}{l}\text { DPPH IC } \\
(\mathrm{mg} / \mathrm{ml})\end{array}$ & $\begin{array}{l}\text { FRAP EC }_{50} \\
(\mathrm{mg} / \mathrm{ml})\end{array}$ & $\begin{array}{c}\text { TAC (mgGAE/g of } \\
\text { extract) }\end{array}$ \\
\hline $\begin{array}{l}\text { Hydromethanolic } \\
(F 0)\end{array}$ & 0.04 & 0.037 & 57.091 & 0.075 & 0.031 & 88.670 \\
\hline Ethyl acetate $(F 1)$ & 0.002 & 0.029 & 21.136 & 0.068 & 0.021 & 39.307 \\
\hline Butanolic $(F 2)$ & 0.007 & 0.021 & 60.803 & 0.089 & 0.047 & 76.482 \\
\hline Aqueous (F3) & 0.009 & 0.039 & 108.006 & 0.092 & 0.035 & 103.850 \\
\hline \multicolumn{7}{|c|}{ Ascorbic acid as positive control $=0.032 \mathrm{mg} / \mathrm{ml}$} \\
\hline
\end{tabular}

et al., using hydromethanolic extraction (methanol-water, 85/ $15, \mathrm{v} / \mathrm{v}$ ) showed that the crude extract of Salvia verbenaca recorded a value of $\mathrm{IC}_{50}=0.0336 \mathrm{mg} / \mathrm{ml}$. This value is better than this obtained in this study [44], and Martins et al. have found that the methanol/water extract of Salvia officinalis has an important antioxidant activity with an $\mathrm{IC}_{50}=0.0329 \mathrm{mg} /$ $\mathrm{ml}$ [45]. Other work carried out by Mekhaldi et al. has shown that the extract of the salvia officinalis records a value of $\mathrm{IC}_{50}=0.0372 \mathrm{mg} / \mathrm{ml}$ [28]. Kontogianni et al. had also found that the ethyl acetate extract of Salvia officinalis exhibits antiradical activity [46]. Krimat et al. also showed that hydromethanolic crude, ethyl acetate, and $n$-butanol fractions of Salvia chudaei Batt exhibited high scavenging activity with IC $_{50}$ values of $0.0192,0.0081$, and $0.0883 \mathrm{mg} / \mathrm{ml}$, respectively [30]. Lu and Foo had evaluated the antioxidant activity of rosmarinic acid and flavonoid derivatives of the Salvia officinalis extract by two methods; scavenging of free radical $\mathrm{DPPH}^{\circ}$ and reduce the $\mathrm{Mo}(\mathrm{IV})$ in $\mathrm{Mo}(\mathrm{V})$. They have therefore noticed that the derivatives of rosmarinic acid were potent antioxidants more than flavonoids [47]. Miliauskas et al. have shown that Salvia officinalis has an important antioxidant activity because of its phenolic compounds [48]. This antioxidant activity is due to the presence of phenolic compounds in the extract [49]. The antioxidant activity of phenolic compounds depends on the structure, in particular the number and positions of the hydroxyl groups on the aromatic rings [50]. In fact, several studies have reported the presence of a direct correlation between antioxidant activity and the reduction power of plant constituents [37]. The level of correlation between phenolic content and antioxidant activity is an interesting aspect, but it should be taken into account that phenolic compounds respond differently in the analysis, depending on the number of phenolic groups they have, and total phenolics content does not incorporate necessarily all the antioxidants that may be present in an extract [32]. After all the combinations made, we record the absence of correlation between the four techniques of antioxidant power and polyphenol content, and this confirmation is widespread in the literature [51]. It is highly accepted that it is not necessarily the high polyphenol content exhibits a potent antioxidant activity [52].

3.5. Antioxidant Activity Measured by Cyclic Voltammetry. Cyclic voltammetry as electrochemical technique has been reported as a simple and rapid analytical tool for estimating the total antioxidant capacity of different components of plant extract. Cyclic voltammetric experiment was performed in sodium acetate-acetic acid buffer solution $(\mathrm{pH}=3.6)$. The total antioxidant capacity of the sample is a function combining two sets of parameters. The first is the oxidation potential, whereas the second is the intensity of the anodic current (Ia), reflecting the concentration of the components [53]. The cyclic voltammograms of gallic acid solutions, in concentrations of 0.007 to $0.06 \mathrm{mg} / \mathrm{mL}$ in the buffer system and with a $\mathrm{pH} 3.6$, were recorded and represented in Figure 3(a). The oxidation peaks in the $400-500 \mathrm{mV}$ region can be observed. The curves of the anodic current (Ipa) as a function of the concentration of gallic acid to obtain calibration line are represented in Figure 3(b).

The resultant relationship $(y=32.97 x+0.536)$, in the gallic acid concentration range of 0.007 to $0.06 \mathrm{mg} / \mathrm{ml}$, is obtained with $R^{2}=0.95$. The cyclic voltammetry leads to better linearity of the calibration curves and to a higher linearity interval. The cyclic voltammograms of the Salvia officinalis hydromethanolic extract from two regions were obtained at a concentration of $0.1 \mathrm{mg} / \mathrm{ml}$ (Figure 4).

In the cyclic voltammograms, the oxidation peaks were observed in the 0.507 and $0.439 \mathrm{mV}$ potentials in the hydromethanolic plant extract from the Boulemane and Khenifra regions, respectively (Table 3 ). The oxidation peak anodic potential (Epa) depends on the antioxidant molecule structure. The phenolic compounds with metadiphenols and isolated phenols, such as t-resveratrol, ferulic acid, morin, vanillic acid, and $p$-coumaric acid, generally, have high oxidation peak potentials compared to those with ortho- or para-diphenol groups, such as morin and tannic acid $[54,55]$. The total antioxidant activity (TAA) of the extract at the concentration of $0.1 \mathrm{mg} / \mathrm{ml}$ was calculated using the calibration curve, of gallic acid as the standard. The peak anodic current (Ipa) values represent the oxidation of the phenolic compounds contained in the hydromethanolic extract of the plant with equal values $\left(\mathrm{Ipa}=24.35\right.$ and $\left.12.33 \mu \mathrm{A} \cdot \mathrm{cm}^{-2}\right)$, respectively, for the Boulemane and Khenifra regions. These results are shown in Table 3. The results show that the highest antioxidant activity in the hydromethanolic extract of Salvia officinalis in the Boulemane region is in the order of $288.8 \mathrm{mgGAE} / \mathrm{g}$ and followed by the Khenifra region in the order of $143.2 \mathrm{mgGAE} / \mathrm{g}$, which shows that the hydromethanolic extract of Salvia officinalis from the Boulemane region is more important than that in the hydromethanolic extract of Salvia officinalis in the Khenifra region. 


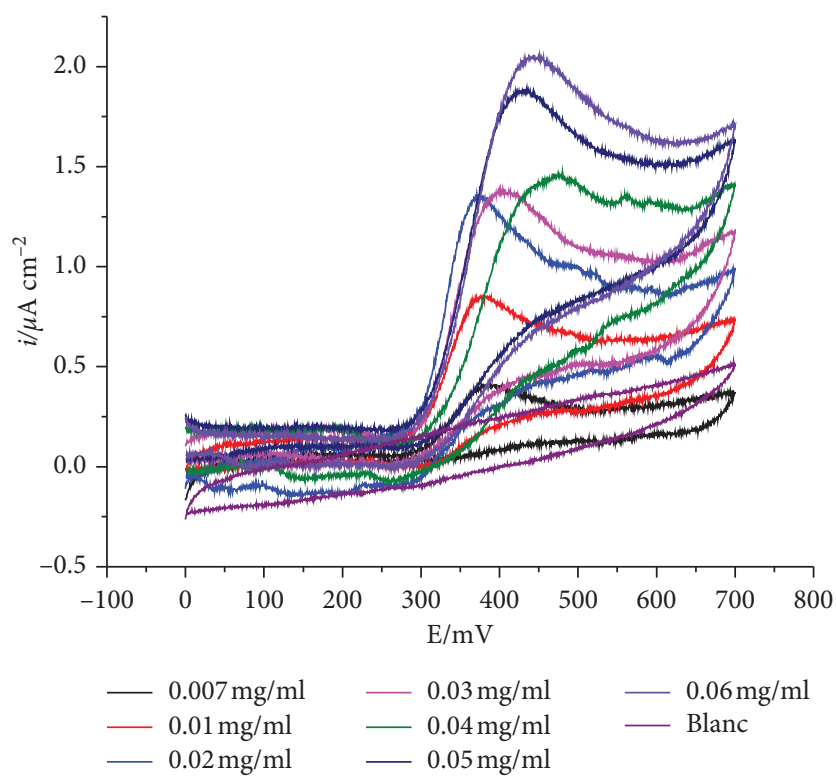

(a)

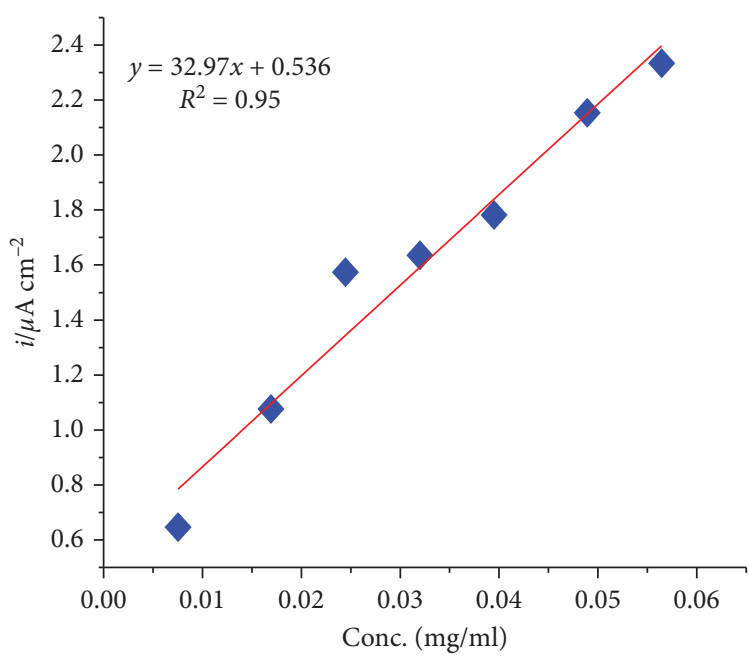

(b)

Figure 3: Cyclic voltammograms of the gallic acid solution at increasing concentrations of 0.003 to $0.06 \mathrm{mg} / \mathrm{ml}$ (a). The curves of the peak anodic current (Ipa) as a function of the concentration of gallic acid (b).

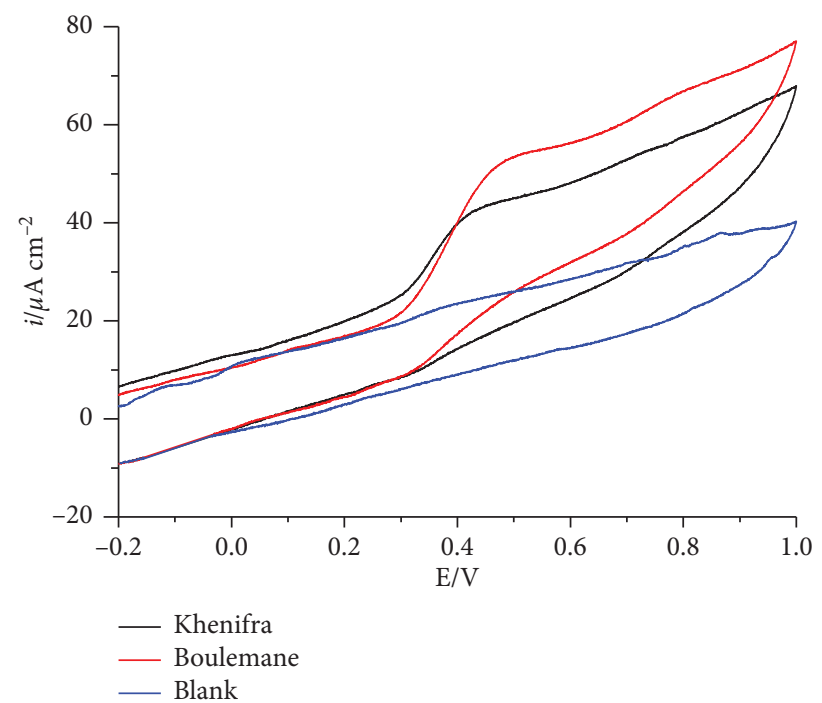

FIgURE 4: Cyclic voltammograms of the Salvia officinalis hydromethanolic extract from Boulemane and Khenifra regions.

TABLE 3: Electrochemical parameters and total antioxidant activity of the hydromethanolic extract of Salvia officinalis L (0.1 mg/mL) for two regions.

\begin{tabular}{lcr}
\hline Regions & Electrochemical parameters & Hydromethanolic extract \\
\hline \multirow{3}{*}{ Boulemane } & Peak anodic potential $(\mathrm{Epa})(\mathrm{V})$ & 0.507 \\
& Peak anodic current $(\mathrm{Ipa})\left(\mathrm{i} / \mu \mathrm{A} \mathrm{cm} \mathrm{cm}^{-2}\right)$ & 24.35 \\
& Concentration $(\mathrm{mgGAE} / \mathrm{ml})$ & 0.722 \\
& Total activity antioxidant $(\mathrm{TAA})(\mathrm{mgGAE} / \mathrm{g})$ & 288.8 \\
Khenifra & Peak anodic potential $(\mathrm{Epa})(\mathrm{V})$ & 0.439 \\
& Peak anodic current $(\mathrm{Ipa})\left(\mathrm{i} / \mu \mathrm{A} \mathrm{cm} \mathrm{cm}^{-2}\right)$ & 12.33 \\
& Concentration $(\mathrm{mg} / \mathrm{ml})$ & 0.358 \\
\hline
\end{tabular}


TABLE 4: Correlation established between phenolic compounds and antioxidant activity of hydromethanolic extracts by different methods.

\begin{tabular}{lcccccr}
\hline & DPPH & FRAP & TAC & TPC & TFC & TCT \\
\hline DPPH & 1 & & & & & \\
FRAP & 0.828 & 1 & & & & \\
TAC & 0.948 & 0.609 & 1 & & & \\
TPC & 0.771 & 0.283 & 0.932 & 1 & & \\
TFC & -0.078 & -0.623 & 0.239 & 0.573 & 1 & \\
TCT & 0.715 & 0.202 & 0.899 & 0.996 & 0.639 & 1 \\
\hline
\end{tabular}

3.6. Correlation between Phenolic Compounds and Antioxidant Activity of Extract and Fractions of Salvia officinalis. In order to reveal the correlation between total concentration of phenols (TPC), flavonoids (TFC), and condensed tannins content (TCT), the antioxidant activity by different methods (DPPH, FRAP, and TAC) is presented in Table 4.

In Table 4 , a strong correlation is observed between TPC and TCT $(R=0.996)$, indicating with high probability that the TPC is mainly responsible for the antioxidant activity of the samples. We have found most important positive correlation between total phenol (TPC), condensed tannins (TCT), and $\mathrm{IC}_{50}$ concentrations with an $R^{2}=0.771$ and 0.715 , respectively, indicating that 77.1 and $71.5 \%$ of the antioxidant capacity of extracts is due to the contribution of phenolic compounds and condensed tannins and that they are the dominant antioxidants in these extracts, but there is no correlation between of total flavonoid content (TFC) and DPPH (Table 4). On the contrary, we noticed a relatively negative mean correlation between FRAP concentrations and total flavonoid content (TFC) with an $R^{2}=-0.623$, and we also find that the low positive correlations were observed between the FRAP and TPC and TCT $\left(R^{2}=0.283\right.$ and 0.202 ), respectively. For total antioxidant capacity (TAC), the strong and positive correlation with total phenol contents (TPC) and condensed tannins (TCT) are greater with $R^{2}=0.932$ and 0.899 , respectively, but for the total flavonoid content (TFC), the correlation of these compounds to reduce $\mathrm{MO}(\mathrm{VI})$ in $\mathrm{Mo}(\mathrm{V})$ is only $23.9 \%$ or the correlation coefficient equal to 0.239 . The high positive correlation between phenolic compounds and different antioxidant activity demonstrated that phenolic compounds may be contributed to antioxidant activity, as it has been reported in other species [56-60]. Table 4 shows the correlations between DPPH, FRAP, and TAC of antioxidant power for the purpose of showing that different methods are complementary and the antioxidant compounds react either as an antioxidant or as an oxidant in the reaction medium of each method. We observed that the concentration of inhibition of DPPH free radicals of phenolic compounds in extracts occurs in one way or another with percentages greater than $80 \%$. The DPPH method has correlation coefficients of the order of $R^{2}=0.828$ and 0.948 corresponding to the methods: FRAP and TAC, respectively. There is also the presence of a significant positive correlation between total antioxidant capacity (TAC) and FRAP with an $R^{2}=0.609$.

\section{Conclusion}

Our data revealed the changes in phytochemical contents along with the antioxidant activity of Salvia officinalis leaves as a function of region and solvent used. The Salvia officinalis had the bioactive compounds (phenolic, flavonoid, and tannin content) which exhibited higher antioxidant activity, and the ethyl acetate, butanol, and aqueous fractions showed the better results in all the in vitro methods of antioxidant assays studied. Furthermore, the correlation observed between the antioxidant activity results and the phenolic as well as the condensed tannin contents although limited indicates that these compounds are among the predominant sources of the antioxidant activity in Salvia officinalis leaves. Finally, DPPH radical scavenging activity, ferric reducing antioxidant power (FRAP), phosphomolybdate reduction (or total antioxidant capacity), and cyclic voltammetry (CV) showed that leaf and hull extracts with potent activity can be introduced as a source of natural antioxidant.

\section{Data Availability}

The authors confirm that all data underlying the findings of this study are fully available without restriction.

\section{Disclosure}

This research did not receive any specific funding.

\section{Conflicts of Interest}

The authors declare that there are no conflicts of interest.

\section{References}

[1] A. K. Meena, P. Bansal, and S. Kumar, "Plants-herbal wealth as a potential source of ayurvedic drugs," Asian Journal of Traditional Medicines, vol. 4, pp. 152-170, 2009.

[2] J. A. Milner, "Functional foods and health promotion," The Journal of Nutrition, vol. 129, no. 7, pp. 1395S-1397S, 1999.

[3] K. Wolfe, X. Wu, and R. H. Liu, "Antioxidant activity of apple peels." Journal of Agricultural and Food Chemistry, vol. 51, no. 3, pp. 609-614, 2003.

[4] A. R. Ndhlala, A. Kasiyamhuru, C. Mupure, K. Chitindingu, M. A. Benhura, and M. Muchuweti, "Phenolic composition of Flacourtia indica, Opuntia megacantha and Sclerocarya birrea," Food Chemistry, vol. 103, no. 1, pp. 82-87, 2007.

[5] T. Kuda, M. Tsunekawa, H. Goto, and Y. Araki, "Antioxidant properties of four edible algae harvested in the Noto Peninsula, Japan," Journal of Food Composition and Analysis, vol. 18, no. 7, pp. 625-633, 2005.

[6] A. Djeridane, M. Yousfi, B. Nadjemi, D. Boutassouna, P. Stocker, and N. Vidal, "Antioxidant activity of some algerian medicinal plants extracts containing phenolic compounds," Food Chemistry, vol. 97, no. 4, pp. 654-660, 2006.

[7] D.-O. Kim, O. K. Chun, Y. J. Kim, H.-Y. Moon, and C. Y. Lee, "Quantification of polyphenolics and their antioxidant capacity in fresh plums." Journal of Agricultural and Food Chemistry, vol. 51, no. 22, pp. 6509-6515, 2003.

[8] L. R. Fukumoto and G. Mazza, "Assessing antioxidant and prooxidant activities assessing antioxidant and prooxidant 
activities of phenolic compounds $\dagger$," Journal of Agricultural and Food Chemistry, vol. 48, no. 8, pp. 3597-3604, 2000.

[9] Y. Weinguang, J. Fischer, and A. Casimir, "Study of anticancer activities of muscadine grape phenolics in vitro," Journal of Agricultural and Food Chemistry, vol. 53, pp. 8804-8812, 2005.

[10] O. I. Aruoma, "Free radicals, oxidative stress, and antioxidants in human health and disease," Journal of the American Oil Chemists' Society, vol. 75, no. 2, pp. 199-212, 1998.

[11] W. R. Leifert and M. Y. Abeywardena, "Cardioprotective actions of grape polyphenols," Nutrition Research, vol. 28, no. 11, pp. 729-737, 2008.

[12] C. Ramassamy, "Emerging role of polyphenolic compounds in the treatment of neurodegenerative diseases: a review of their intracellular targets," European Journal of Pharmacology, vol. 545, no. 1, pp. 51-64, 2006.

[13] Z. Tayarani-najaran, J. Asili, and S. A. Emami, "Growth inhibition and apoptosis induction of Salvia chloroleuca on MCF-7 breast cancer cell line," Iranian Journal of Pharmaceutical Research, pp. 789-799, 2013.

[14] C. S. C. Garcia, C. Menti, A. P. F. Lambert et al., "Pharmacological perspectives from Brazilian Salvia officinalis (Lamiaceae): antioxidant, and antitumor in mammalian cells," Anais da Academia Brasileira de Ciências, vol. 88, no. 1, pp. 281-292, 2016.

[15] M. Adams, F. Gmünder, and M. Hamburger, "Plants traditionally used in age related brain disorders-a survey of ethnobotanical literature," Journal of Ethnopharmacology, vol. 113, no. 3, pp. 363-381, 2007.

[16] D. Stagos, N. Portesis, C. Spanou et al., "Correlation of total polyphenolic content with antioxidant and antibacterial activity of 24 extracts from Greek domestic Lamiaceae species," Food and Chemical Toxicology, vol. 50, no. 11, pp. 4115-4124, 2012.

[17] M. R. A. Rodrigues, L. K. S. Kanazawa, T. L. M. d. Neves et al., "Antinociceptive and anti-inflammatory potential of extract and isolated compounds from the leaves of Salvia officinalis in mice," Journal of Ethnopharmacology, vol. 139, no. 2, pp. 519-526, 2012.

[18] R. K. Al-Barazanjy, K. Dizaye, and A. Al-Asadye, "Cytotoxic and cytogenetic effects of salvia officinalis on different tumor cell lines," Middle East Journal of Internal Medicine, vol. 6, no. 4, pp. 15-25, 2013.

[19] A. Al-Asadye and M. Esmaeilizadeh, "Pharmacological properties of Salvia officinalis and its components," Journal of Traditional and Complementary Medicine, vol. 7, no. 4, pp. 433-440, 2017.

[20] M. I. Azevedo, A. F. Pereira, R. B. Nogueira et al., "The antioxidant effects of the flavonoids rutin and quercetin inhibit oxaliplatin-induced chronic painful peripheral neuropathy," Molecular Pain, vol. 9, pp. 1744-8069, 2013.

[21] D. Dah-nouvlessounon, H. Adoukonou-sagbadja, N. Diarrassouba et al., "Phytochemical analysis and biological activities of cola nitida bark," Biochemistry Research International, vol. 2015, Article ID 493879, 12 pages, 2015.

[22] V. L. Singleton and J. A. Rossi, "Colorimetryof total phenolics with phosphomolybdic-phosphotungstic acid reagent," American Journal of Enology and Viticulture, vol. 16, pp. 144-158, 1965.

[23] S. Amalich, K. Fadili, M. Fahim, F. E. L. Hilali, and T. Zaïr, "Polyphenols content and antioxidant power of fruits and leaves of Juniperus phoenicea L. From Tounfite (Morocco)," Moroccan Jorunal Chemistry, vol. 1, pp. 177-186, 2016.

[24] A. Skendi, M. Irakli, and P. Chatzopoulou, "Analysis of phenolic compounds in Greek plants of Lamiaceae family by
HPLC," Journal of Applied Research on Medicinal and Aromatic Plants, vol. 6, pp. 62-69, 2017.

[25] Y. Y. Lim, T. T. Lim, and J. J. Tee, "Antioxidant properties of several tropical fruits: a comparative study," Food Chemistry, vol. 103, no. 3, pp. 1003-1008, 2007.

[26] M. Lung and W. Huang, "Antioxidant properties of polysaccharides from Laetiporus sulphureus in submerged cultures," African Journal of Biotechnology, vol. 11, pp. 6350-6358, 2012.

[27] P. Prieto, M. Pineda, and M. Aguilar, "Spectrophotometric quantitation of antioxidant capacity through the formation of a phosphomolybdenum complex: specific application to the determination of vitamin E." Analytical Biochemistry, vol. 269, no. 2, pp. 337-341, 1999.

[28] M. Abdelkader, B. Ahcen, D. Rachid, H. Hakim, and A. P. Materiel, "Phytochemical study and biological activity of sage," International Journal of Bioengineering and Life Sciences, vol. 8, pp. 1253-1257, 2014.

[29] A. Alimpić, N. Kotur, B. Stanković et al., "The in vitro antioxidative and cytotoxic effects of selected Salvia species water extracts," Journal of Applied Botany and Food Quality, vol. 88, pp. 115-119, 2015.

[30] S. Krimat, T. Dob, M. Toumi, A. Kesouri, and A. Noasri, "Assessment of phytochemicals, antioxidant, antimicrobial and cytotoxic properties of Salvia chudaei Batt. et Trab. endemic medicinal plant from Algeria," Journal of Materials and Environmental Science, vol. 6, pp. 70-78, 2015.

[31] G. Topçu, M. Ay, A. Bilici, C. Sarıkürkcü, M. Öztürk, and A. Ulubelen, "A new flavone from antioxidant extracts of Pistacia terebinthus," Food Chemistry, vol. 103, no. 3, pp. 816-822, 2007.

[32] K. Tawaha, F. Alali, M. Gharaibeh, M. Mohammad, and T. Elelimat, "Antioxidant activity and total phenolic content of selected Jordanian plant species," Food Chemistry, vol. 104, no. 4, pp. 1372-1378, 2007.

[33] E. Hayouni, M. Abedrabba, M. Bouix, and M. Hamdi, "The effects of solvents and extraction method on the phenolic contents and biological activities in vitro of Tunisian Quercus coccifera L. and Juniperus phoenicea L. fruit extracts," Food Chemistry, vol. 105, no. 3, pp. 1126-1134, 2007.

[34] A. M. El-waziry, "Nutritive value assessment of ensiling or mixing Acacia and Atriplex using in vitro gas production technique," Research Journal of Agriculture and Biological Sciences, vol. 3, pp. 605-614, 2007.

[35] R. Ksouri, W. Megdiche, H. Falleh et al., "Influence of biological, environmental and technical factors on phenolic content and antioxidant activities of Tunisian halophytes." Comptes Rendus Biologies, vol. 331, no. 11, pp. 865-873, 2008.

[36] D. Atmani, N. Chaher, M. Berboucha et al., "Antioxidant capacity and phenol content of selected Algerian medicinal plants," Food Chemistry, vol. 112, no. 2, pp. 303-309, 2009.

[37] A. Yildirim, A. Mavi, and A. A. Kara, "Determination of antioxidant and antimicrobial activities of Rumex crispus L. extracts," Journal of Agricultural and Food Chemistry, vol. 49, no. 8, pp. 4083-4089, 2001.

[38] J. Hubert, "Caractérisation biochimique et propriétés biologiques des micronutriments du germe de soja-etude des voies de sa valorisation en nutrition et santé humaines," 2006.

[39] R. L. Prior, X. Wu, and K. Schaich, "Standardized methods for the determination of antioxidant capacity and phenolics in foods and dietary supplements," Journal of Agricultural and Food Chemistry, vol. 53, no. 10, pp. 4290-4302, 2005.

[40] S. Athamena, I. Chalghem, A. Kassah-Laouar, and S. L. E. S. Khebri, "Activite anti-oxydante et antimicrobienne 
D'extraits de Cuminum cyminum L.” Lebanese Science Journal, vol. 11, pp. 69-81, 2010.

[41] L. E. Rojo, J. Benites, J. López et al., “Antioxidant capacity and polyphenolic content of twelve traditionally used herbal medicinal infusions from the South American Andes," Boletin Latinoamericano y del Caribe de Plantas Medicinales y Aromaticas, vol. 8, pp. 498-508, 2009.

[42] N. Turkmen, Y. Velioglu, F. Sari, and G. Polat, "Effect of extraction conditions on measured total polyphenol contents and antioxidant and antibacterial activities of black tea." Molecules, vol. 12, no. 3, pp. 484-496, 2007.

[43] S. Bourgou, R. Ksouri, A. Bellila, I. Skandrani, H. Falleh, and B. Marzouk, "Phenolic composition and biological activities of Tunisian Nigella sativa L. shoots and roots." Comptes Rendus Biologies, vol. 331, no. 1, pp. 48-55, 2008.

[44] F. Belkhiri, A. Baghiani, M. M. Zerroug, and L. Arrar, "Investigation of antihemolytic, xanthine oxidase inhibition, antioxidant and antimicrobial properties of Salvia verbenaca L. Aerial Part Extracts," African Journal of Traditional, Complementary and Alternative Medicines, vol. 14, no. 2, pp. 273-281, 2017.

[45] N. Martins, L. Barros, C. Santos-Buelga, M. Henriques, S. Silva, and I. C. F. R. Ferreira, "Evaluation of bioactive properties and phenolic compounds in different extracts prepared from Salvia officinalis L." Food Chemistry, vol. 170, pp. 378-385, 2015.

[46] V. G. Kontogianni, G. Tomic, I. Nikolic et al., "Phytochemical profile of Rosmarinus officinalis and Salvia officinalis extracts and correlation to their antioxidant and anti-proliferative activity," Food Chemistry, vol. 136, no. 1, pp. 120-129, 2013.

[47] Y. Lu and L. Yeap Foo, "Antioxidant activities of polyphenols from sage (Salvia officinalis)," Food Chemistry, vol. 75, no. 2, pp. 197-202, 2001.

[48] G. Miliauskas, P. R. Venskutonis, and T. A. Van Beek, "Screening of radical scavenging activity of some medicinal and aromatic plant extracts," Food Chemistry, vol. 85, no. 2, pp. 231-237, 2004.

[49] H. Fenglin, L. Ruili, H. bao, and M. Liang, "Free radical scavenging activity of extracts prepared from fresh leaves of selected Chinese medicinal plants," Fitoterapia, vol. 75, no. 1, pp. 14-23, 2004.

[50] N. Balasundram, K. Sundram, and S. Samman, "Phenolic compounds in plants and agri-industrial by-products: antioxidant activity, occurrence, and potential uses," Food Chemistry, vol. 99, no. 1, p. 191, 2006.

[51] T. Sun, J. Powers, and J. Tang, "Evaluation of the antioxidant activity of asparagus, broccoli and their juices," Food Chemistry, vol. 105, no. 1, pp. 101-106, 2007.

[52] A. Moure, J. M. Cruz, D. Franco et al., "Natural antioxidants from residual sources," Food Chemistry, vol. 72, no. 2, pp. 145-171, 2001.

[53] D. Zielinska, D. Szawara-Nowak, and H. Zielinski, "Comparison of spectrophotometric and electrochemical methods for the evaluation of the antioxidant capacity of buckwheat products after hydrothermal treatment," Journal of Agricultural and Food Chemistry, vol. 55, no. 15, pp. 6124-6131, 2007.

[54] E. S. Gil and R. O. Couto, "Flavonoid electrochemistry: a review on the electroanalytical applications," Revista Brasileira de Farmacognosia, vol. 23, no. 3, pp. 542-558, 2013.

[55] P. A. Kilmartin, H. Zou, and A. L. Waterhouse, "A cyclic voltammetry method suitable for characterizing antioxidant properties of wine and wine phenolics," Journal of Agricultural and Food Chemistry, vol. 49, no. 4, pp. 1957-1965, 2001.
[56] J. C. M. Barreira, I. C. F. R. Ferreira, M. B. P. P. Oliveira, and J. A. Pereira, "Antioxidant activity and bioactive compounds of ten Portuguese regional and commercial almond cultivars," Food and Chemical Toxicology, vol. 46, no. 6, pp. 2230-2235, 2008.

[57] A. Sousa, I. C. F. R. Ferreira, L. Barros, A. Bento, and J. A. Pereira, "Effect of solvent and extraction temperatures on the antioxidant potential of traditional stoned table olives "alcaparras"," LWT-Food Science and Technology, vol. 41, no. 4, pp. 739-745, 2008.

[58] L. Barros, P. Baptista, L. M. Estevinho, and I. C. F. R. Ferreira, "Effect of fruiting body maturity stage on chemical composition and antimicrobial activity of Lactarius sp. mushrooms," Journal of Agricultural and Food Chemistry, vol. 55, no. 21, pp. 8766-8771, 2007.

[59] A. A. Hatamnia, A. Rostamzad, P. Malekzadeh et al., “Antioxidant activity of different parts of Pistacia khinjuk stocks fruit and its correlation to phenolic composition," Natural Product Research, vol. 30, no. 12, pp. 1445-1450, 2015.

[60] A. A. Hatamnia, N. Abbaspour, and R. Darvishzadeh, “Antioxidant activity and phenolic profile of different parts of Bene (Pistacia atlantica subsp. kurdica) fruits," Food Chemistry, vol. 145, pp. 306-311, 2014. 